\title{
Introduction - The MDGs and Beyond: Pro-poor Policy in a Changing World
}

\author{
Andy Sumner and Claire Melamed
}

Abstract This issue of the IDS Bulletin is dedicated to discussing and reviewing the MDGs and the global effort that grew from the UN Millennium Declaration. This article provides an overview of this IDS Bulletin and introduces the key themes.

\begin{abstract}
We will spare no effort to free our fellow men, women and children from the abject and dehumanizing conditions of extreme poverty, to which more than a billion of them are currently subjected.

(The Millennium Declaration of the UN General Assembly - resolution 55/2,

8 September 2000)
\end{abstract}

\section{Introduction}

Nearly ten years have passed since that declaration and the context has changed radically. The Millennium Development Goals (MDGs) were an approach born of a benign era of relative stability, stronger economic growth and fairly buoyant aid budgets. We now face a very different world. Changes sparked by increased uncertainty and a growing sense of multiple insecurities have the potential to impact adversely on levels of poverty. The economic crisis itself has led to significant changes in the context for international development (see discussion in McGulloch and Sumner 2009; Sumner and Tiwari 2008). The crisis/post-crisis context is, of course, central to many MDG questions not only in terms of crisis impacts on the MDGs and poverty but also in the impact on development commitments internationally and nationally over the next ten years.

The articles here seek to inform debate in 2010, leading up to and beyond the UN MDG review summit in September and to reflect on the MDG experience so far, and ask what that experience means for the next five years and beyond.
Important recurring debates include: what have the MDGs actually achieved, and for whom? What can we learn from the MDGs about how the international community can best play a role in national processes of development and poverty reduction? Will the MDGs prove to reflect an international commitment to poverty reduction that goes beyond 2015, or are they the product of a specific moment, unlikely to be repeated?

The articles are drawn from discussions at a DFID-DSA-EADI-ActionAid policy forum in June 2009. ${ }^{1}$ The debates at that forum and the articles published here are just a starting point and reflect a wider ongoing ferment in pro-poor policy, Indicators and architecture, illustrated by initiatives such as the Sarkozy Commission, the OECD-convened Measuring the Progress of Societies Project, the Oxford Poverty and Human Development Initiative, the Wellbeing in Developing Countries (WeD) research programme and UNU WIDER Frontiers of Poverty Analysis programme, to name just a few. There is also the newly established annual European Development Report.

\section{What are the MDGs for?}

The MDGs are different things to different people. They are a set of Indicators, but they are also an idea or 'global norm' for poverty reduction, an incentive structure for pro-poor development and a view of 'development' in themselves. Perhaps the defining question is: how do global agreements and conventions change poor people's lives? For example, Manning (2009) 
argues that the MDGs should be taken 'to encourage sustainable pro-poor development progress and donor support of domestic efforts in this direction'. Hulme (this IDS Bulletin) argues that the MDGs are a global norm institutionalising poverty reduction but what is needed now is 'strategies to shift international norms so that the citizens of the present rich countries ... and future rich countries ... find the existence of extreme poverty in an affluent world morally unacceptable'.

The MDG 'paradigm' itself can be seen as a broader 'human development meets results-based management' (see again Hulme, this IDS Bulletin) consisting of the quantitative Targets of the MDGs but be extended to the much broader Millennium Declaration (Maxwell 2005).

Advocates of the MDG approach believe it provides a rallying call for placing multidimensional poverty reduction at the centre of development efforts. The MDGs are thus viewed as a set of Indicators for guiding poverty reduction and for holding international agencies and governments accountable to citizens. Those less convinced see the MDG approach, however, as a donor-led, reductionist agenda that pays little attention to locally defined and owned definitions of progress and development. Some of these perceptions might help to explain why academic writing has often tended not to take an explicit MDG-lens to poverty and policy discussions (of course there is much writing that is about poverty but not via an MDG-lens).

There is an enormous amount of writing on the MDGs from the UN and wider afield. There is the UN's Annual MDG Report and National MDG Reports as well as the main report and numerous sub-reports of the UN Millennium Project (UNMP 2005), and the IMF/World Bank's Annual Monitoring Report. Most recently, Sanjay Reddy and others at Colombia have conducted a multicountry study of 30 countries (UNDP 2009).

Academic writing on the MDGs has been dominated by discussion of MDG concepts, costings and feasibility. There is a body of literature that simply critiques or outright rejects the usefulness of the MDGs to a greater or lesser extent for the choice of Indicators or how the MDGs seek to frame or conceptualise (or not) or distort 'development' (e.g. Biccum 2005; Black and White 2003; Easterly 2009; Gaiha 2003; James 2006; Saith 2006; Satterthwaite 2003).

In contrast, there is a body of literature that is more practical and concerned with asking 'how to do it?' or more fundamentally 'is it possible to do?'. For example, there has been numerous discussions on MDG costings and the feasibility (or tracking) of the MDGs (for a range of discussion, see Atkinson 2006; Bourguignon et al. 2009; Chakravarty and Majumber 2008; Clemens et al. 2007; Demery and Walton 1999; Hanmer et al. 1999; Hanmer and Naschold 2001; Nelson 2007; Reddy and Heuty 2005; Roberts 2005).

More recently, and a trigger to this IDS Bulletin issue, was the emergence of an 'MDG impacts' literature (e.g. Fukuda-Parr 2008; Hulme 2007; Manning 2009) about the MDG impacts to date - in terms of adoption (in policy), allocation (of resources) and adaptation (to locally defined Goals, Indicators and Targets) and what the impacts mean looking forward.

\section{MDG impacts so far}

Have the MDGs significantly changed the policy or practice of development - and at what level, and what might this mean for MDG momentum and looking further forward? As Manning (this IDS Bulletin) notes in his article, the impact of the MDGs on international development discourse has been immense. However, as he points out, in the absence of a counterfactual, it is inevitably impossible to judge whether the MDGs were the cause of any perceived or actual shift in donor priorities or whether both were the consequence of a change in donors' thinking about development that preceded both. Manning goes on to discuss, looking at actual spending patterns for example, that it is possible that the MDGs have had the impact of pushing donor spending towards the social sectors, since social Indicators provided the bulk of the Targets.

In contrast, Fukuda-Parr (this IDS Bulletin), reviewing donor priorities and measuring them against the MDGs, finds weaker links between the stated priorities of donors and the MDGs. What many commentators agree on is that more attention is needed to the productive sectors. This is evident in the neglect of agriculture (noted in the World Development Report 2008, World Bank 2007), and the renewed focus on growth in the UK's Department for International 
Development, among other agencies (e.g. DFID 2009 and Solheim, this IDS Bulletin) which will inevitably lead, if slowly, to a shift in spending and in priority setting on the international stage.

A second impact issue around influence is how far the MDGs have affected policymaking and policy dialogues within developing countries themselves. Here the evidence is also hard to come by. Fukuda-Parr's review of how far PRSPs have incorporated the MDGs shows that MDGs are partially integrated into national level planning, but that some references do exist. Richard Manning suggests that the MDGs have helped some civil society groups to hold governments in developing countries to account for their decisions. However, the fact that the evidence is so partial implies that much more research is needed on how global and national level impacts can both be maximised and properly articulated with each other. The UNDP (2009) recent study of 30 countries is important here and revealing (as Manning notes in this IDS Bulletin). Some 25 of those 30 countries had added, expanded or modified Indicators and ten had added local Goals. An important question that needs researching is why is it that some countries have clear evidence of national ownership of the MDGs and others have little or none?

These discussions so far focus on the impact of the MDGs on policymaking rather than on actual outcomes for poor people for methodological reasons. Clearly, the question of the counterfactual is particularly intractable when trying to identify the myriad factors influencing outcomes for any particular household or individual. Indeed, Fischer contends that it is hard to trace any specific impact of the MDGs on poverty. First, this is because the transmission mechanisms are unclear, given the very real difficulty of proving a link between aid and poverty reduction, and second because data on poverty has faced a particular challenge in recent years following the World Banks' revision of its purchasing power parity (PPP) estimates and the consequent large changes to the estimates of the scale of global poverty. A further challenge is posed on the Indicators by Mekonen (this IDS Bulletin), who argues that a focus on quantity above quality has led to less effective interventions in education. However, Jolly (this IDS Bulletin), in a review of the success of specific Targets relating to the eradication of diseases such as smallpox, provides a useful reminder of the impact of clear quantitative Targets, if they are the right ones and if there is sufficient political will behind them.

\section{What to do differently?}

What is required to build MDG momentum to 2015 and beyond? There are a set of issues around whether the MDGs have got it 'right' on the Targets chosen and the Indicators used to measure effectiveness - and, by implication, a discussion on how it might be done differently and better between 2010 and 2015 and beyond. There are a number of cross-cutting issues that have risen in prominence since 2000 as a result of changing discourses such as climate, gender and equity (see respectively in this IDS Bulletin, Urban, Jones et al., and various on equity - Jahan, Fukuda-Parr, Vandemoortele and Delamonica). These issues were around in 2000 but less prominent and less integrated into MDGs than they might have been, and many authors ask how to bring these cross-cutting issues in.

A further question, related to this is around 'paradigms' (see Gore, this IDS Bulletin, in particular). Do the MDGs still reflect what we know about what is important about how 'development' happens and how policy can influence that process? New and emerging 'paradigmatic' lenses for thinking about development and what development is about include those that were well established in 2000 such as rights (see Robinson and Langford, both in this IDS Bulletin) and those that have come to the fore since, or are 'bubbling under' such as wellbeing (see McGregor and Sumner, this IDS Bulletin), social protection (see Jones et al., this IDS Bulletin) and universalism (see Fischer, this IDS Bulletin).

With their privileging of certain Indicators over others, and their global focus, the MDGs have inevitably sparked off a debate on whether these are the right Indicators. We have accumulated ten years of experience on 'what works' in development since the MDGs were agreed in 2000 , and inevitably ideas about what to incentivise and how have shifted in that time. A key issue raised by a number of contributors is around disaggregation of Indicators and data (i.e. equity issues and the poorest).

In relation to gender, Jones et al. (this IDS Bulletin) argue that lack of disaggregation cannot 
only reduce the life chances of women and girls, but also result in less effective development policy, if social factors such as the gender division of labour in agriculture are not taken into account. Jahan (this IDS Bulletin) also argues the importance of disaggregation of data along a number of lines, to get a true picture of the impact of policy on outcomes.

The MDGs are all about absolute measures of poverty - attendance at school, dollars-per-day of income and so on. But in recent years, greater attention has been paid to the importance of relative poverty. Manning, Fukuda-Parr and Fischer (all in this IDS Bulletin) all argue that greater attention should be paid to issues of relative poverty. Introducing equity inevitably leads to a more highly politicised discussion around global poverty - if we are worried about incomes at the top as well as at the bottom of the distribution, will this inevitably open the door to discussions around global redistribution? Fischer indicates that his might be a useful way forward. In contrast, Vandermoortele (this IDS Bulletin) focuses on inequalities at the national level and suggests a practical way of incorporating an equity dimension into any new indicators of poverty, and illustrates how this could work with reference to the under-five mortality rate.

In many ways the development discourse has changed radically since 2000, and even more since the mid-1990s when most of the Goals that now make up the MDGs were being discussed and agreed. One key difference has been the greater emergence of 'rights-based approaches' the idea that the achievement of human rights both political and economic rights - is the key Goal of development. This is an approach which puts poor people themselves at the centre of things - in order to achieve their human rights they must be active participants in the process. A number of articles in this IDS Bulletin reflect this shift, and the more political approach to the development choices which follow from it.

Both Robinson and Langford (this IDS Bulletin) argue that a focus on rights would lead to much greater focus on the process of development. Within countries, this would involve greater attention to political participation, and for the Goals as a whole, a recognition that how they are achieved matters, not just whether they are achieved. Jones et al. (this IDS Bulletin) also point to the importance of improving the voice and agency of women in the development process, if policy choices and outcomes are to meet their needs. The idea of rights is also taken up by Manning and Fukuda-Parr (this IDS Bulletin), reflecting the growing academic and policy interest in this area.

A further emergent approach is that of 'wellbeing'. McGregor and Sumner (this IDS Bulletin), seek to broaden the discussion to build MDG momentum via thinking more about the emergent concept of ' 3 -D wellbeing' (the dynamic interaction of material wellbeing, relational wellbeing and subjective/perceptual wellbeing) and what it offers policies to achieve the MDGs in terms of 'capability' policy interventions and 'conditions' policy interventions (across material, relational and subjective/perceptual wellbeing).

A cursory look at the MDGs reveals one further highly significant shift in thinking between then and now - climate - and the importance of achieving development within a given level of carbon emissions is notably absent from all the Goals apart from the rather poorly defined Goal 7. As both Erik Solheim and Frauke Urban (both this IDS Bulletin) note, any future thinking will have to give much greater attention to the importance of low-carbon development, and related issues around equity, financing and future access to technology that form the heart of international negotiations in this area.

\section{Beyond 2015?}

Although the academic and policy debates around how to measure development, how to incorporate rights and equity, and how to track the impact of past policy choices are important, any agreement will be made by politicians, and like any other international agreement, will have to balance international aspirations with domestic political realities. What matters then, as Wickstead (this IDS Bulletin) reminds us, is: do the MDGs still have political resonance? He argues convincingly that 'far from losing their political resonance, in fact, the MDGs have retained their ability to act as a rallying point for development progress'.
A brief history of the MDGs and the global political momentum that created them is provided by Hulme's article (this IDS Bulletin). 
He provides a useful reminder of the long and difficult process of getting the MDGs agreed the first time around. He argues that in order to get that level of agreement again, a new idea will be needed to provide the campaigning and political will to complete a difficult negotiation.

Vandermoortele (this IDS Bulletin), with experience of the process the last time around, sounds a warning about trying to achieve anything too quickly - speed might come at the expense of getting the right agreement, and involving the right people.

There are different views about whether the agreement should be primarily focused at a national or a global level. Vandermoortele and Manning both argue here that the Targets are global and that it is not necessarily appropriate to try to apply them nationally. Jahan and Mekonen (this IDS Bulletin) both assert the importance of having Targets that are relevant and appropriate to the national level. Hulme tries to bridge the two perspectives by arguing that any future agreement should seek better links between global goals and national policies to achieve these goals. Jones et al. provide a specific illustration of how this could happen with reference to gender - with global pressure from a UN agency for women - and global goals operationalised through gender budgeting and policy analysis at a national level.

Indeed, the real questions that require urgent attention are around politics. Why have some countries 'nationalised' or 'localised' the MDGs and others have not and can the global political momentum that led to the MDGs be renewed in different times? The debate around what, if anything, can and should succeed the MDGs after 2015 is still in its very early stages and many fear talking about this will derail the

\section{Note}

1 See Tribe and Lafon's summary of plenary proceedings (this IDS Bulletin) and also: www.bit.ly/after2015 momentum for the MDGs. There is a lack of empirical evidence around the impact of the MDGs thus far on which to base any conclusions, and the parameters of what we want the MDGs to do, and for whom, are not yet set. It is also a debate which may prove to be purely theoretical unless strong political momentum develops behind the assertion that there is a need for any successor agreement to the MDGs. However, as the articles in this IDS Bulletin, and the many conversations over this year and next will likely demonstrate, it is sure to go to the heart of what international development is all about.

The good news is what we can do now, which we could not do in 2000 , is to have a genuinely global, coordinated process of roundtables, voices of the poor, blogging and uploaded videos. Think Ravi Kanbur's World Development Report 2000/1 pre-process + Voices of the Poor + Web 2.0. Think of tweeting the UN Secretary General with your idea.

We could imagine the global process around the Poverty WDR 2000/1 plus the new technologies for a global discussion. The global process might culminate in an international meeting on a 'new development consensus' perhaps with some greater emphasis on Africa as several authors discuss - notably Wickstead, Mekonen and Nhema, all in this IDS Bulletin). Important components would be building on the key achievement of the current MDG consensus; recognising global developmental and humanities common interests; and new approaches to or architectures for international development cooperation built perhaps not on aid but new forms of financing (climate/flight taxes or financial market taxes) and rights, wellbeing and equity indicators. Watch this space. 


\section{References}

Atkinson, A.B. (2006) 'Funding the Millennium Development Goals: A Challenge for Global Public Finance', European Review 14.4: 555-64

Biccum, A.R. (2005) 'Development and the "New" Imperialism: A Reinvention of Colonial Discourse in DFID Promotional Literature', Third World Quarterly 26.6: 1005-20

Black, R. and White, H. (2003) Targeting Development: Critical Perspectives on the Millennium Development Goals, London: Routledge

Bourguignon, François; Bénassy-Quéré, Agnès; Dercon, Stefan; Estache, Antonio; Gunning, Jan Willem; Kanbur, Ravi; Klasen, Stephan; Maxwell, Simon; Platteau, Jean-Philippe and Spadaro, Amede (2009) Millennium Development Goals at Midpoint: Where Do We Stand and Where Do We Need to Go? Paper for the joint European Commission initiative 'Mobilising European Research for Development Policies', Paris: Centre for Economic Policy

Chakravarty, S. and Majumber, A. (2008) 'Millennium Development Goals: Measuring Progress Towards their Achievement', Journal of Humanitarian Development 9.1: 109-29

Clemens, Michael; Kenny, Charles and Moss, Todd (2007) 'The Trouble with MDGs: Confronting Expectations of Aid and Development Success', World Development 35.5: 735-51

Demery, L. and Walton, M. (1999) 'Are the Poverty and Social Goals for the 21 st Century Attainable?', IDS Bulletin 30.2: 75-80

DFID (2009) Eliminating World Poverty: Building Our Common Future, White Paper, London: HMSO

Easterly, W. (2009) 'How the Millennium Development Goals are Unfair to Africa', World Development 37.1: 26-35

Fukuda-Parr, S. (2008) Are the MDGs Priority in Development Strategies and Aid Programmes? Only Few Are!, IPG Working Paper 48, Brasilia: UNDP International Poverty Centre

Gaiha, R. (2003) 'Are the Millennium Goals of Poverty Reduction Useful?', Oxford Development Studies 31.1: 59-84

Hanmer, L. and Naschold, F. (2001) 'Attaining the International Development Targets: Will Growth be Enough?', Development Policy Review 18: 11-36

Hanmer, L.; De Jong, N.; Kurian, R. and Mooij, M. (1999) 'Are the DAC Targets Achievable? Poverty and Human Development in the Year 2015', Journal of International Development 11.4: 547-63
Hulme, D. (2007) The Making of the Millennium Development Goals: Human Development Meets Results-Based Management in an Imperfect World, BWPI Working Paper 16, Manchester: University of Manchester

James, J. (2006) 'Misguided Investments in Meeting Millennium Development Goals: A Reconsideration Using Ends-based Targets', Third World Quarterly 27.3: 443-58

Manning, R. (2009) Using Indicators to Encourage Development: Lessons from the MDGs. DIIS Report 2009:01, Copenhagen: Danish Institute for International Studies

Maxwell, S. (2005) The Washington Consensus is Dead! Long Live the Meta-Narrative!, ODI Working Paper 243, London: Overseas Development Institute

McCulloch, N. and Sumner, A. (2009) 'Will the Global Financial Crisis Change the Development Paradigm?', IDS Bulletin 40.5: 101-8

Nelson, P.J. (2007) 'Human Rights, the Millennium Development Goals, and the Future of Development Cooperation', World Development 35.12: 2041-55

Reddy, S. and Heuty, A. (2005) 'A Practical Approach to Achieving the Millennium Development Goals', Journal of Human Development and Capabilities 6.3: 399-420

Roberts, J. (2005) 'Millennium Development Goals: Are International Targets Now More Credible?', Journal of International Development 17.1: 113-29

Saith, A. (2006) 'From Universal Values to Millennium Development Goals: Lost in Translation', Development and Change 37.6: 1167-99

Satterthwaite, D. (2003) The Millennium Development Goals and Local Processes, London: International Institute for Environment and Development: 7-46

Sumner, A. and Tiwari, M. (2008) After 2015: International Development Policy at a Crossroads, Basingstoke: Palgrave Macmillan

UNDP (2009) Beyond the Midpoint: Accelerating Support for MDG Achievements, New York: United Nations Development Programme UNMP (2005) Investing in Development: A Practical Plan to Achieve the Millennium Development Goals, Overview, UN Millennium Project 2005

World Bank (2007) World Development Report 2008: Agriculture for Development, World Bank: Washington DG 